\title{
Role of Transforming Growth Factor- $\beta 1$ in Regulating Fetal-Maternal Immune Tolerance in Normal and Pathological Pregnancy
}

Dongyong Yang ${ }^{1 \dagger}$, Fangfang Dai ${ }^{1+}$, Mengqin Yuan ${ }^{1}$, Yajing Zheng ${ }^{1}$, Shiyi Liu ${ }^{1}$, Zhimin Deng ${ }^{1}$, Wei Tan ${ }^{1}$, Liping Chen ${ }^{1}$, Qianjie Zhang ${ }^{1}$, Xiaomiao Zhao ${ }^{2 *}$ and Yanxiang Cheng ${ }^{1 *}$

OPEN ACCESS

Edited by:

Aldo Tagliabue,

Italian National Research Council,

Italy

Reviewed by:

Francis Lin,

University of Manitoba, Canada

Gabriela Dveksler,

Uniformed Services University of the

Health Sciences, United States

*Correspondence:

Yanxiang Cheng

yanxiangCheng@whu.edu.cn

Xiaomiao Zhao

zhxmiao@mail.sysu.edu.cn

${ }^{t}$ These authors have contributed equally to this work and

share first authorship

Specialty section:

This article was submitted to Immunological Tolerance and Regulation,

a section of the journal

Frontiers in Immunology

Received: 31 March 2021 Accepted: 13 August 2021 Published: 31 August 2021

Citation:

Yang D, Dai F, Yuan $M$, Zheng $Y$,

Liu S, Deng Z, Tan W, Chen L, Zhang Q, Zhao X and Cheng Y (2021) Role of Transforming Growth Factor-

$\beta 1$ in Regulating Fetal-Maternal

Immune Tolerance in Normal and Pathological Pregnancy.

Front. Immunol. 12:689181 doi: 10.3389/fimmu.2021.689181
1 Department of Obstetrics and Gynecology, Renmin Hospital of Wuhan University, Wuhan, China, 2 Department of Obstetrics and Gynecology, Sun Yat-sen Memorial Hospital, Sun Yat-sen University, Guangzhou, China

Transforming growth factor- $\beta$ (TGF- $\beta$ ) is composed of three isoforms, TGF- $\beta 1$, TGF- $\beta 2$, and TGF- $\beta 3$. TGF- $\beta 1$ is a cytokine with multiple biological functions that has been studied extensively. It plays an important role in regulating the differentiation of immune cells and maintaining immune cell functions and immune homeostasis. Pregnancy is a carefully regulated process. Controlled invasion of trophoblasts, precise coordination of immune cells and cytokines, and crosstalk between trophoblasts and immune cells play vital roles in the establishment and maintenance of normal pregnancy. In this systematic review, we summarize the role of TGF- $\beta 1$ in regulating fetal-maternal immune tolerance in healthy and pathological pregnancies. During healthy pregnancy, TGF- $\beta 1$ induces the production of regulatory $T$ cells (Tregs), maintains the immunosuppressive function of Tregs, mediates the balance of M1/M2 macrophages, and regulates the function of NK cells, thus participating in maintaining fetal-maternal immune tolerance. In addition, some studies have shown that TGF- $\beta 1$ is dysregulated in patients with recurrent spontaneous abortion or preeclampsia. TGF- $\beta 1$ may play a role in the occurrence and development of these diseases and may be a potential target for the treatment of these diseases.

Keywords: transforming growth factor- $\beta 1$, pregnancy, immune tolerance, recurrent spontaneous abortion, preeclampsia

\section{INTRODUCTION}

Transforming growth factor- $\beta$ (TGF- $\beta$ ), an evolutionarily conserved secreted protein consisting of three isoforms, TGF- $\beta 1$ (the most common), TGF- $\beta 2$, and TGF- $\beta 3$, which map to regions of human chromosomes 19q13.1-q13.3, 1q41 (1), and 14q23-24 (2), respectively (3). The role of TGF- $\beta$ in cell growth, proliferation, differentiation, metabolism, and apoptosis has gradually attracted attention since $1980(4,5)$. Pro-TGF- $\beta 1$ monomers are composed of a 249 -residue domain at the amino terminus, a pro-protein convertase cleavage site, and a 112-residue domain at the carboxyl terminus. TGF- $\beta 1$ usually exists in the form of latent TGF- $\beta 1$. Latent TGF- $\beta 1$ combines with latent TGF- $\beta$ binding proteins (LTBPs) or glycoprotein-A repetitions predominant protein (GARP) to form large latent complexes $(6,7)$. Increasing evidence shows that TGF- $\beta 1$ plays an indispensable 
role in regulating immune cell differentiation, maintaining immune cell function, and immune homeostasis (8-11).

Healthy pregnancy is a process requiring precise regulation that depends on the balance between the invasion of trophoblast cells and fetal-maternal immune tolerance. The precise coordination and action of various immune cells and cytokines is the key to maintaining fetal-maternal immune tolerance (12). Studies have shown that TGF- $\beta 1$ plays an important role in trophoblast cell invasion, maintenance of fetal-maternal immune tolerance, and uterine spiral artery remodeling (13-15). In addition, as a multifunctional cytokine, TGF- $\beta 1$ is widely involved in the regulation of immune cell function and plays an indispensable role in fetal-maternal immune tolerance (16). Therefore, in this review, we specifically focus on the mechanism of TGF- $\beta 1$ in the fetal-maternal immune tolerance. In addition, we discuss its potential role in the occurrence and development of recurrent spontaneous abortion (RSA) and preeclampsia (PE).

\section{TGF- $\beta 1$}

\section{TGF- $\beta 1$ Activation}

TGF- $\beta 1$ is produced in the form of a precursor. The precursor undergoes processing, such as signal peptide removal, homodimerization, and proprotein convertase cleavage, to produce carboxy-terminal dimers (mature TGF- $\beta 1$ ) and aminoterminal dimers (latency-associated peptide, LAP). Mature TGF- $\beta 1$ and LAP combine in a noncovalent form to form latent TGF- $\beta 1$ (17). Both immune cells and nonimmune cells can secrete latent TGF- $\beta 1$. There are two main mechanisms for the extracellular fixation of latent TGF- $\beta 1$. In the first, TGF- $\beta 1$ binds to extracellular matrix (ECM) proteins and is deposited in the ECM, which mainly occurs in fibroblasts and epithelial cells. In the second, latent TGF$\beta 1$ covalently binds to the transmembrane leucine-rich repeat protein GARP and is maintained on the cell surface, a process that mainly occurs in regulatory T cells (Tregs) (18).

Latent TGF- $\beta 1$ is inactive because LAP prevents mature TGF- $\beta 1$ from binding to receptors. The process of releasing mature TGF- $\beta 1$ from latent TGF- $\beta 1$ is called TGF- $\beta 1$ activation (19). The TGF- $\beta 1$ activation mechanisms include integrin-mediated LAP deformation and release of mature TGF- $\beta 1$, proteolysis, physicochemical factors, and deglycosylation. These mechanisms have been well summarized in a previous review (20). Here, we emphasize the TGF- $\beta 1$ activation effect of pregnancy-specific glycoproteins (PSGs). PSGs are encoded by the Psg gene on chromosome 19 and are expressed by syncytiotrophoblast cells throughout human pregnancy. There are 10 kinds of PSGs in humans, namely, PSG1-PSG9 and PSG11. PSG1 and PSG9 have previously been confirmed to activate latent TGF- $\beta 1$, and PSG1 can also inhibit dextran sodium sulfate-induced colitis in mice in a TGF$\beta$-dependent manner $(21,22)$. It is worth noting that in subsequent studies, researchers have found that all 10 human PSGs can activate TGF- $\beta 1$, and mouse PSG23 can also activate TGF- $\beta 1$ in a dosedependent manner (23). These findings indicate that PSGs are important activators of TGF- $\beta 1$, and PSGs may play important roles in maintaining immune tolerance during pregnancy by activating TGF- $\beta 1$.

\section{TGF- $\beta 1$ Signaling Pathway}

Once activated, mature TGF- $\beta 1$ binds to high-affinity cell surface-specific receptors and activates downstream signaling pathways to perform corresponding biological functions. Activated extracellular TGF- $\beta 1$ binds with the transmembrane kinase receptor TGF- $\beta$ type I receptor (T $\beta$ R-I) and TGF- $\beta$ type II receptor (T $\beta \mathrm{R}-\mathrm{II})$ at the cell surface to form a heterotetrameric complex, leading to the phosphorylation and activation of the receptors (24). Subsequently, receptor kinases phosphorylate and activate intracellular cascade signals, including the classic small mother against decapentaplegic (SMAD)-dependent and SMAD-independent pathways (Figure 1), and then mediate diverse biological effects $(3,25,26)$. SMADs are composed of spherical $N$-terminal DNA-binding domains (MHIs) and $C$ terminal domains (MHIIs), including receptor-regulated SMADs (SMAD1, SMAD2, SMAD3, SMAD5, and SMAD8), common-partner SMAD (SMAD4), and inhibitory SMADs (SMAD6 and SMAD7) $(25,27)$. In the SMAD-dependent pathway, activated transmembrane receptors phosphorylate serine (Ser) residues at MHII of SMAD2 and SMAD3. Phosphorylated SMAD2 and/or SMAD3 can form a trimeric complex with SMAD4 and then undergo transfer to the nucleus to regulate gene expression $(28,29)$. In addition to SMADdependent pathways, TGF- $\beta 1$ can also activate SMADindependent pathways such as PI3K-AKT, p38 MAPK, NF- $\mathrm{BB}$, and ERK to regulate gene expression and participate in regulating cell functions (30-33).

\section{TGF- $\beta 1$ IN FETAL-MATERNAL IMMUNE TOLERANCE}

After fertilization, the embryo attaches to the endometrium, and semiallogeneic fetal extravillous trophoblasts (EVTs) begin to invade the uterine mucosa without being rejected by the maternal immune system $(34,35)$. Once they have invaded into the decidua, EVTs encounter different maternal cell types, such as decidual macrophages, uterine NK (uNK) cells, and Tregs. The moderate invasion of trophoblasts, precise coordination of immune cells and cytokines, and crosstalk between EVTs and immune cells are essential for the establishment and maintenance of a normal pregnancy (36, 37). Tregs, NK cells, macrophages, and other immune cells play vital roles in maintaining fetal-maternal immune tolerance. These immune cells regulate each other and maintain immune homeostasis by secreting proinflammatory or anti-inflammatory cytokines (38). TGF- $\beta 1$ is a cytokine that exerts a negative regulatory function. It plays important roles in the differentiation of Tregs, the balance of M1/M2 macrophages, and the regulation of NK cell functions.

\section{TGF- $\beta 1$ and Tregs}

$\mathrm{CD} 4{ }^{+} \mathrm{CD} 25^{+}$Tregs are a key subset of $\mathrm{T}$ lymphocytes. Both thymus-derived Tregs and peripherally induced Tregs can act as effective inhibitors of inflammatory immune responses and mediate immune homeostasis (39). Natural Tregs depend on 


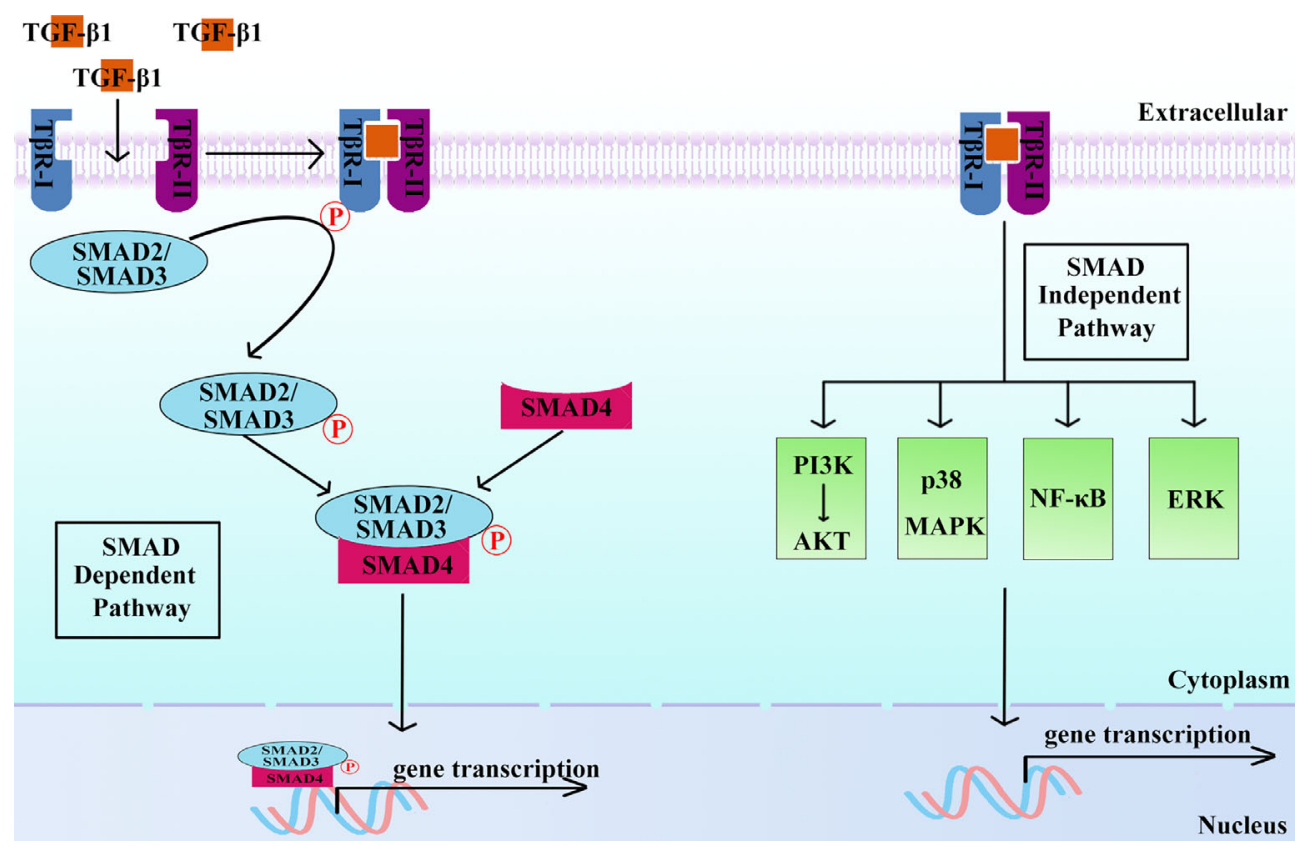

FIGURE 1 | Active TGF- $\beta 1$ functions via SMAD-dependent and/or SMAD-independent pathways. SMAD-dependent pathway: After TGF- $\beta 1$ binds to specific receptors on the cell surface, phosphorylated T $\beta R$-I recruits and phosphorylates SMAD2 and SMAD3. Phosphorylated SMAD2 and/or SMAD3 combine with SMAD4 to form a trimeric complex, which can regulate gene expression in the nucleus. SMAD-independent pathway: After TGF- $\beta 1$ binds to receptors, phosphorylated T $\beta R-I$ recruits and phosphorylates signaling molecules, such as PI3K-AKT, p38 MAPK, NF-KB, and ERK, and participates in the regulation of gene expression.

the maturation of the thymus, and TGF- $\beta 1$ is an important inducer of peripheral Tregs (40). FOXP3 is the most specific Treg marker. It is expressed in the thymus and peripheral Tregs regardless of the mode and state of Treg activation (41). The FOXP3 gene is highly conserved between humans and mice. Mice lacking Foxp3 usually die of lethal lymphoproliferative autoimmune syndrome, and humans with FOXP3 mutations suffer from an autoimmune syndrome called IPEX (42, 43). Continuous expression of FOXP3 is necessary to maintain the suppressive immune function of Tregs. Tregs in Foxp3-deficient mice lack immunosuppressive function, and Foxp3 transfection can confer $\mathrm{CD} 4^{+} \mathrm{CD} 25^{+} \mathrm{T}$ cells the ability to inhibit the proliferation of $\mathrm{CD} 4^{+} \mathrm{T}$ cells (44).

During pregnancy, the maternal immune system undergoes systemic changes to accommodate the growth and development of fetuses expressing paternal antigens. This immune tolerance is regulated by the number and immunosuppressive functions of Tregs. The number of Tregs increases rapidly in the first trimester, reaches a peak in the second trimester, and gradually decreases to the prepregnancy level during delivery $(39,45)$. Studies have shown that the proportion of Tregs in the peripheral blood of pregnant women and mice increases significantly during pregnancy, and the specific recruitment of Tregs from maternal peripheral blood to the fetal-maternal interface makes the proportion of Tregs in the placenta and decidua higher than that in peripheral blood (46). Tregs at the maternal-fetal interface prevent fetal rejection by creating an immune tolerance microenvironment characterized by the expression of
IL-10, TGF- $\beta 1$, and heme oxygenase isoform 1 (HO- 1 ) (47). The level and function of Tregs are related to the occurrence and development of pregnancy-related complications such as RSA and PE. CD $25^{+}$Treg depletion can cause embryo implantation failure in allogeneic mice (48). Compared with normal pregnant women, women with spontaneous abortion have a lower level of $\mathrm{CD} 4{ }^{+} \mathrm{CD} 25^{+}$Tregs (49). It has been appreciated that immunotherapy with paternal or third-party lymphocytes is an effective method of treatment for unexplained RSA (URSA) (50, 51). After immunotherapy with monocytes from the infant's father, expression of the transcription factor ROR $\gamma \mathrm{t}$ in Th17 cells in peripheral blood mononuclear cells of URSA patients decreased, while expression of the Treg-specific transcription factor FOXP3 increased, and secretion of the cytokine TGF- $\beta 1$ related to Tregs increased (52). These results indicate that the Th17/Treg balance is conducive to normal pregnancy, and TGF$\beta 1$ seems to be an important factor in regulating the balance of Tregs/Th17 at the maternal-fetal interface.

Tregs can regulate the immune response and maintain immune tolerance through a cell contact-dependent mechanism and a cell contact-independent mechanism. The cell contactindependent mechanism of Tregs is achieved through the secretion of inhibitory cytokines, and TGF- $\beta 1$ is essential for the proliferation and inhibitory activity of Tregs (53). The activation of TGF- $\beta 1$ is necessary to induce the production of $\mathrm{CD}^{+}{ }^{+} \mathrm{FOXP} 3^{+}$ Tregs, and Tregs can then secrete TGF- $\beta 1$ and participate in immune regulation $(54,55)$. Studies have shown that TGF- $\beta 1$ can promote the differentiation of initial $\mathrm{CD} 4^{+} \mathrm{T}$ cells into Tregs, and 
TGF- $\beta 1$ secreted by Tregs can play a role in maintaining the inhibitory properties of Tregs by binding to its receptors. The use of neutralizing antibodies against TGF- $\beta 1$ or TGF- $\beta 1$ expression defects in Tregs will result in the weakening or disappearance of Treg inhibitory activity (56-58). The expression of Foxp3 in TGF$\beta^{-1-}$ mouse peripheral blood Treg cells was significantly reduced, and the exogenous addition of TGF- $\beta 1$ could promote the expression of Foxp3 (59). In the CBA/J $\times$ DBA/2 abortionprone mouse model, adoptive transfer of Tregs enhanced the concentration of TGF- $\beta 1$ in mouse serum and reduced the abortion rate (60). Similarly, applying recombinant IL-17 (a hallmark cytokine secreted by Th17 cells) to the vaginal fornix of pregnant $\mathrm{CBA} / \mathrm{J}$ mice mated with $\mathrm{BALB} / \mathrm{c}$ males significantly increased the abortion rate and reduced TGF- $\beta$ mRNA and protein levels. Adoptive transfer of pregnancyinduced Tregs from 14-day normal pregnant mice before mating offsets the adverse effects caused by IL-17 (61). These results indicate that TGF- $\beta 1$ is indispensable for maintaining the function of Tregs. Simultaneously, TGF- $\beta 1$ plays an important role in mediating the fetal-maternal immune tolerance regulated by Tregs, but the specific mechanism requires further study.

\section{TGF- $\beta 1$ and NK Cells}

NK cells are important components of the endometrial innate immune system and play an important role in the maintenance of pregnancy. In the initial phase of pregnancy, NK cells are preferentially recruited to the endometrium to play an immunomodulatory role under the effect of chemokines derived from endometrial stromal and trophoblast cells (62). TGF- $\beta 1$ produced by decidual stromal cells can convert CD $56{ }^{\text {dim }} \mathrm{CD} 16^{+} \mathrm{NK}$ cells into $\mathrm{CD} 56^{\text {bright }} \mathrm{CD} 16^{-} \mathrm{NK}$ cells to complete the terminal differentiation of NK cells $(63,64)$. Decidual NK (dNK) cells are mainly of the CD56 $6^{\text {bright }} \mathrm{CD} 16$ phenotype, constituting between 50 and $70 \%$ of the total lymphocytes of the decidua, and they are the most abundant immune cells in the decidua (65). Low cytotoxic dNK cells can regulate vascular remodeling at the maternal-fetal interface by producing vascular endothelial growth factor, angiopoietin, and TGF- $\beta 1$ (66-68). An emerging mechanism by which mesenchymal stem cells (MSCs) regulate the immune function of dNK cells has gradually attracted more attention (69). Studies suggest that menstrual blood stromal/stem cells (MenSCs), a substitute for endometrial MSCs, can induce the proliferation of NK cells. However, MenSCs pretreated with IFN- $\gamma$ can suppress NK cell proliferation by releasing TGF- $\beta$ and IL-6 (70). These results indicate that TGF- $\beta 1$ is an important mediator that regulates the function of $\mathrm{dNK}$ cells and plays an important role in the maintenance of fetal-maternal immune tolerance.

\section{TGF- $\beta 1$ and Macrophages}

Almost $20-30 \%$ of the leukocytes in the decidua in the first trimester are macrophages. Macrophages play important roles in trophoblast cell invasion, vascular remodeling, and immune tolerance (71). Macrophages are classified into two subpopulations: classic M1 and alternative M2 macrophages. M1 macrophages express proinflammatory factors such as IL-6, IL-12, and TNF- $\alpha$. Conversely, M2 macrophages upregulate the expression of anti-inflammatory cytokines such as TGF- $\beta 1$ and IL-10 (72). The elaborate balance between M1 macrophages and M2 macrophages is of prime importance to establish and maintain pregnancy (73-75). M2 macrophages promote cell homeostasis by secreting TGF- $\beta 1$ and IL-10, which has a profound impact on maintaining the immune tolerance environment (76).

Macrophages not only regulate local immune function but also directly promote the migration and invasion of extravillous trophoblast cells and support spiral artery remodeling and angiogenesis (77). Coculture of trophoblasts and macrophage cell lines can promote the polarization of macrophages to M2, and expression of the marker proteins TGF- $\beta 1$ and IL-10 via the IL-6/STAT3 pathway and M2 macrophages can promote the invasion and migration of trophoblasts (78). Unlike NK cells, which are only located in the decidua, macrophages exist in both the decidua and the placenta and are the major immune cell population in the placenta. Placental macrophages have also shown an M2-like phenotype; genes related to M1 are silenced by hypermethylation, while genes related to M2 are hypomethylated (79). A recent study has shown that placental macrophages have two cytokine expression patterns. In the first pattern, placental macrophages produce reduced levels of IL-1, IL-6, IL-10, IL-8, and TNF $\alpha$ and can be stimulated by bacterial endotoxins. In the second pattern, placental macrophages constitutively express IL-11, IL-17A, IL-17F, TGF- $\beta 1$, and VEGF, and this expression is unresponsive to stimulation (80). Taken together, this evidence reveals that TGF- $\beta 1$ plays an important role in regulating the function of macrophages at the maternal-fetal interface.

\section{TGF- $\beta 1$ and Regulatory B Cells}

Regulatory B cells (Bregs), a new type of B cell population, have a negative immunomodulatory effect. Bregs are a collective term for a variety of regulatory B cell subgroups, accounting for approximately $0.5 \%$ of the total number of $\mathrm{B}$ cells in healthy people (81). Similar to Tregs, Bregs can maintain immune tolerance by producing different inhibitory cytokines (such as IL-10, IL-35, and TGF- $\beta 1$ ) or through cell contact-dependent mechanisms (82). Bregs can interact with Tregs, macrophages, and dendritic cells to participate in the regulation of immune homeostasis (83). A large number of studies have found that Bregs also play an important role in maintaining fetal-maternal immune tolerance. Studies have shown that increased levels of $\mathrm{CD} 5^{+} \mathrm{CD} 1 \mathrm{~d}^{+}$Breg cells can reduce immune abortion in pregnant mice. The adoptive transfer of Bregs to abortion-prone mice can enhance the function of Tregs and maintain the immature state of DCs to enhance maternal immune tolerance (84). In addition, estrogen can also induce the maturation of Bregs during pregnancy to maintain immune tolerance (85).

Bregs play a key role in the downregulation of the inflammatory response through an IL-10-dependent mechanism (86). In addition, compared with normal mice, the percentage of Bregs expressing IL-35 in the peripheral blood of abortive mice is reduced, suggesting the potential involvement of IL-35 in pregnancy maintenance (87). Can the TGF- $\beta 1$ released by Bregs also participate in the regulation of the immune balance of the 
maternal-fetal interface? At present, research is lacking on Bregs involved in regulating the immune tolerance of the maternal-fetal interface by releasing TGF- $\beta 1$. Considering that Bregs are an established source of TGF- $\beta 1$, TGF- $\beta 1$ can regulate a variety of immune cell functions, including Tregs, and the important role of Bregs during pregnancy, more in-depth research remains to be conducted.

\section{TGF- $\beta 1$ IN PATHOLOGICAL PREGNANCY}

The two key events of normal human pregnancy are embryo implantation and placenta formation (88). During these events, the maternal immune system must accept the genetically incompatible fetuses to allow trophoblast invasion (89). It is known that pregnancy-related diseases, such as RSA and PE, may be closely related to impaired immune tolerance $(90,91)$. TGF- $\beta 1$ is an important regulator of immune cell function. Understanding the role of TGF- $\beta 1$ in the occurrence and development of RSA and PE may help to further reveal the etiology of these diseases.

\section{RSA}

RSA refers to two or more consecutive spontaneous abortions before 20 weeks of pregnancy, and its incidence is approximately $5 \%$ (92-94). Studies have confirmed that compared with healthy controls, the expression of TGF- $\beta 1$ in the decidual tissue of RSA patients is significantly decreased $(95,96)$. Treatment with vasoactive intestinal peptide (VIP) in a miscarriage-prone mouse model $(\mathrm{CBA} / \mathrm{J} \times \mathrm{DBA} / 2)$ can regulate the endocytosis of maternal macrophages and promote the expression of TGF- $\beta 1$ at the implantation site of the mouse, significantly increasing the number of implant points (97). In addition, Ma et al. (98) found that endovascular extravillous trophoblasts (enEVTs) actively produced TGF- $\beta 1$, and primary enEVTs promoted the differentiation of naive $\mathrm{CD}^{+} \mathrm{T}$ cells into immunosuppressive Tregs in a TGF- $\beta 1$-dependent manner. The proportion of TGF$\beta 1$-producing enEVTs and their ability to educate Tregs differentiation were significantly reduced in RSA patients. Overall, TGF- $\beta 1$ may participate in the occurrence and development of RSA by regulating immune tolerance.

The TGF- $\beta 1$ signaling pathway can regulate fetal-maternal immune tolerance by regulating the expression of indoleamine 2,3-dioxy (IDO), thereby participating in immune and inflammatory responses (99). In semen, high concentrations of TGF- $\beta 1$ and TGF- $\beta 2$ can regulate women's immune tolerance to sperm, embryo implantation, and subsequent pregnancy. After intercourse, the $\mathrm{pH}$ of the vagina will activate TGF- $\beta$-involved immune tolerance (100). Furthermore, existing studies show that TGF- $\beta$ seems to be a factor controlling the apoptosis and proliferation of endometrial cells during the process of embryo implantation. Every subtype of TGF- $\beta$ has a different effect on the endometrium; TGF- $\beta 1$ and TGF- $\beta 2$ can induce the apoptosis of uterine cells, while TGF- $\beta 3$ has a proliferation-promoting effect (26). In summary, in addition to immune cells, TGF- $\beta 1$ is also involved in maintaining the functions of nonimmune cells.

\section{PE}

$\mathrm{PE}$ is a pregnancy-specific disease characterized by new hypertension and proteinuria after 20 weeks of gestation. Its global incidence is approximately 5-8\% (101). PE can be divided into two different subtypes: early-onset PE (appearing before 34 weeks) and late-onset PE (appearing after 34 weeks). The pathogenesis between these two subtypes is different (102). Although some theories have been proposed to explain PE, its pathogenesis has not yet been elucidated.

A study found that compared with the control group, the expression of TGF- $\beta 1$ in maternal and cord blood of late-onset $\mathrm{PE}$ was significantly reduced, but there was no significant difference in that of early-onset PE (103). However, most studies have not clearly pointed out whether PE patients have early- or late-onset PE. For example, in a study on the TGF- $\beta 1$ single nucleotide polymorphism and the risk of $\mathrm{PE}$ in Chinese women, the researchers did not indicate whether PE patients were early- or late-onset. PE patients were divided into mild PE and severe PE. It was found that the allelic variant of TGF- $\beta 1$ rs1800469 T was associated with the risk of PE, and TGF- $\beta 1$ rs $1800469 \mathrm{~T}>\mathrm{C}$ was negatively correlated with the severity of PE (104). In addition, a study has shown that compared with healthy controls, the expression of TGF- $\beta 1$ and Smad3 is upregulated in the placenta of patients with PE (105), while another study has shown no significant difference in the expression level of TGF- $\beta 1$ in the serum of controls and PE patients (106). These contradictory results may be due to the different tissues tested, the racial differences in the subjects studied, and the small number of subjects in some studies. In addition, these studies rarely mentioned whether the detected TGF- $\beta 1$ was active. It should be noted that due to ethical requirements, most clinical specimens of PE are derived from the placenta obtained after delivery (>34 weeks), which cannot well reflect the early development of PE. Therefore, these research results should be considered with caution. Establishing TGF- $\beta 1$ testing standards and carrying out large-scale clinical sample testing may be effective solutions to determine whether the expression level of TGF- $\beta 1$ is related to PE.

Impaired trophoblast cell invasion and increased uterine placental vascular resistance in early pregnancy are important pathological mechanisms of PE (107). TGF- $\beta 1$ is involved in regulating the invasion of human trophoblast cells $(108,109)$. Compared with healthy controls, the transcription level of TGFB 1 and the level of active TGF- $\beta 1$ protein are increased in the placental tissue of patients with $\mathrm{PE}$. The TGF- $\beta 1 / \mathrm{Smad} 3$ signaling pathway can mediate the inhibition of trophoblast cell migration and invasion caused by the downregulation of lysyl oxidase (LOX) (110). Liu (111) et al. found that TGF- $\beta 1 / \mathrm{Smad} 3$ can also mediate the inhibitory effect of miR-142-3p on the invasion and migration of trophoblast cells in vitro. In addition, TGF- $\beta 1$ is also involved in the regulation of endothelial cell function. Endoglin is a coreceptor of TGF- $\beta$ signaling. Soluble endoglin increases significantly in the serum of PE patients, and its level is related to the severity of PE. Soluble endoglin can block the vasodilation induced by TGF- $\beta 1$ in rats by inhibiting the binding of TGF- $\beta 1$ to its receptor (112). A study on the 
underlying mechanism between maternal PE and fetal vascular function found that compared with the offspring of healthy controls, the TGF- $\beta 1$ signaling network in HUVECs of maternal PE offspring was impaired. Maternal PE can promote the proliferation of female fetal HUVECs induced by TGF- $\beta 1$, but it has no effect on the proliferation of male fetal HUVECs induced by TGF- $\beta 1$. These findings suggest that TGF- $\beta 1$ may be involved in the regulation of endothelial cell function, and maternal PE plays different roles in the regulation of female and male fetal endothelial cell function (113). Although the above studies have not clearly pointed out whether PE is early- or late-onset PE, they indicate that TGF- $\beta 1$ may participate in the occurrence and development of $\mathrm{PE}$ by regulating the invasion of trophoblast cells and the function of vascular endothelial cells.

$\mathrm{PE}$ is related to abnormalities of the immune system throughout the body and the placenta. Studies have shown that compared with healthy controls, the level of TGF- $\beta 1$ in the decidua of PE patients (not indicating early- or late-onset $\mathrm{PE}$ ) is increased, and high levels of TGF- $\beta 1$ can inhibit the activation of specific subgroups of $\mathrm{dNK}$ cells, thereby participating in the occurrence of PE (114). In addition, a mass spectrometry study found that the level of PSG9 in the serum of women with earlyonset PE was significantly higher than that in the control group, and PSG9 may be a potential marker of PE (115). Another study has shown that PSG9 can bind to LAP and activate potential TGF- $\beta 1$ to induce the production of $\mathrm{FoxP}^{+}$Tregs, indicating that PSG9 may be involved in inducing immune tolerance at the fetal-maternal interface (21). These results are contradictory, and the role of PSG9 in the pathogenesis of PE remains to be revealed by more in-depth studies. Although these results suggest that TGF- $\beta 1$ may participate in the occurrence of PE by regulating immune tolerance, further research is needed to explore the role and specific mechanisms of TGF- $\beta 1$.

\section{CONCLUSION}

In summary, TGF- $\beta 1$ plays an important role in regulating the function of immune cells at the maternal-fetal interface and maintaining immune homeostasis. TGF- $\beta 1$ can induce the production of Tregs, regulate the balance of Tregs/Th17, and is necessary to maintain the suppressive immune function of Tregs. In addition, TGF- $\beta 1$ can induce the production of CD56 ${ }^{\text {bright }}$ CD16 NK cells, and TGF- $\beta 1$ released by $\mathrm{dNK}$ cells participates in the regulation of vascular remodeling at the maternal-fetal interface. Furthermore, TGF- $\beta 1$ plays a vital role in regulating the M1/M2 balance. TGF- $\beta 1$ is a cytokine secreted by Tregs, NK cells, and M2 macrophages. It may be an important molecule that coordinates the balance of immune cells at the maternal-fetal interface and maintains immune tolerance.

During pregnancy, TGF- $\beta 1$ and TGF- $\beta 2$ induce endometrial cell apoptosis, while TGF- $\beta 3$ promotes endometrial cell proliferation. The differential regulation of TGF- $\beta$ subtypes on endometrial cells may be the key regulatory mechanism of endometrial decidualization. In addition, TGF- $\beta 1$ is differentially expressed in RSA tissues, and the dysregulation of TGF- $\beta 1$ may be related to the occurrence and development of RSA. Although the expression level of TGF- $\beta 1$ in the decidua and serum of patients with $\mathrm{PE}$ is still controversial, an increasing number of studies have shown that TGF- $\beta 1$ can participate in the occurrence and development of PE by affecting the invasion ability of trophoblast cells and the activation of $\mathrm{dNK}$ cells. Therefore, TGF- $\beta 1$ may be a potential therapeutic target for these diseases, and the role of TGF- $\beta 1$ in the immune tolerance of the maternal-fetal interface may provide new clues for the immunological treatment of pregnancy-related complications.

Because TGF- $\beta 1$ plays a key role in regulating trophoblast cell invasion and fetal-maternal immune tolerance, the development of specific drugs targeting TGF- $\beta 1$ for the treatment of pregnancy-related diseases may have broad prospects. However, since TGF- $\beta 1$ is expressed in almost all cells, strategies to target the drug to the maternal-fetal interface to function face challenges that must be overcome.

Current studies have certain limitations. For example, many studies do not clearly indicate which TGF- $\beta$ subtype was studied but instead described it as TGF- $\beta$, raising confusion and obstacles to summarizing the functions of TGF- $\beta 1$ and its role in diseases. In addition, most studies on the relationship between TGF- $\beta 1$ and immune cells were carried out in cell lines. The use of human or mouse primary cells may be more conducive to revealing the true role of TGF- $\beta 1$ in regulating immune cell function. In future studies, standardizing the expression and detection standards of TGF- $\beta$ subtypes and conducting more primary cell or in vivo studies may further reveal the role of TGF- $\beta 1$ in pathophysiological conditions.

\section{AUTHOR CONTRIBUTIONS}

DY, FD, XZ and YC proposed this idea. FD, DY, MY, SL, YZ, WT, ZD, LC and QZ performed the PubMed search. FD and DY drafted the manuscript. XZ and YC edited/reviewed this review. All authors agree to be accountable for the content of the work. All authors contributed to the article and approved the submitted version.

\section{FUNDING}

This review was supported by the National Key R\&D Program of China (grant number 2018YFC1003200), the National Natural Science Foundation of China (grant number 81860276, 82071655), China Medical Association Clinical Medical Research Special Fund Project (grant number 17020310700), the Fundamental Research Funds for the Central Universities (grant number 2042020kf1013), Educational and Teaching Reform Research Project (grant number 413200095), and Graduate credit course projects (grant number 413000206). 


\section{REFERENCES}

1. Fujii D, Brissenden JE, Derynck R, Francke U. Transforming Growth Factor Beta Gene Maps to Human Chromosome 19 Long Arm and to Mouse Chromosome 7. Somat Cell Mol Genet (1986) 12(3):281-8. doi: 10.1007/ BF01570787

2. Barton DE, Foellmer BE, Du J, Tamm J, Derynck R, Francke U. Chromosomal Mapping of Genes for Transforming Growth Factors Beta 2 and Beta 3 in Man and Mouse: Dispersion of TGF-Beta Gene Family. Oncogene Res (1988) 3(4):323-31.

3. Larson C, Oronsky B, Carter CA, Oronsky A, Knox SJ, Sher D, et al. TGFBeta: A Master Immune Regulator. Expert Opin Ther Targets (2020) 24 (5):427-38. doi: 10.1080/14728222.2020.1744568

4. Massague J. Tgfbeta Signalling in Context. Nat Rev Mol Cell Biol (2012) 13 (10):616-30. doi: 10.1038/nrm3434

5. Border WA, Noble NA. Transforming Growth Factor Beta in Tissue Fibrosis. N Engl J Med (1994) 331(19):1286-92. doi: 10.1056/NEJM19941 1103311907

6. Hinck AP, Mueller TD, Springer TA. Structural Biology and Evolution of the TGF-Beta Family. Cold Spring Harb Perspect Biol (2016) 8(12):a022103. doi: 10.1101/cshperspect.a022103

7. Dong X, Zhao B, Iacob RE, Zhu J, Koksal AC, Lu C, et al. Force Interacts With Macromolecular Structure in Activation of TGF-Beta. Nature (2017) 542(7639):55-9. doi: 10.1038/nature21035

8. Cen S, Wang P, Xie Z, Yang R, Li J, Liu Z, et al. Autophagy Enhances Mesenchymal Stem Cell-Mediated CD4(+) T Cell Migration and Differentiation Through CXCL8 and TGF-Beta1. Stem Cell Res Ther (2019) 10(1):265. doi: 10.1186/s13287-019-1380-0

9. Zhou Q, Qin S, Zhang J, Zhon L, Pen Z, Xing T. 1,25(OH)2D3 Induces Regulatory T Cell Differentiation by Influencing the VDR/PLC-Gamma1/ TGF-Beta1/Pathway. Mol Immunol (2017) 91:156-64. doi: 10.1016/ j.molimm.2017.09.006

10. Tu E, Chia CPZ, Chen W, Zhang D, Park SA, Jin W, et al. T Cell ReceptorRegulated TGF-Beta Type I Receptor Expression Determines T Cell Quiescence and Activation. Immunity (2018) 48(4):745-59.e6. doi: 10.1016/ j.immuni.2018.03.025

11. Cuende J, Lienart S, Dedobbeleer O, van der Woning B, De Boeck G, Stockis J, et al. Monoclonal Antibodies Against GARP/TGF-Betal Complexes Inhibit the Immunosuppressive Activity of Human Regulatory T Cells in Vivo. Sci Transl Med (2015) 7(284):284ra56. doi: 10.1126/scitranslmed.aaa1983

12. Ander SE, Diamond MS, Coyne CB. Immune Responses at the MaternalFetal Interface. Sci Immunol (2019) 4(31):eaat6114. doi: 10.1126/ sciimmunol.aat6114

13. Graham CH, Lysiak JJ, McCrae KR, Lala PK. Localization of Transforming Growth Factor-Beta at the Human Fetal-Maternal Interface: Role in Trophoblast Growth and Differentiation. Biol Reprod (1992) 46(4):561-72. doi: 10.1095/biolreprod46.4.561

14. Zhao MR, Qiu W, Li YX, Zhang ZB, Li D, Wang YL. Dual Effect of Transforming Growth Factor Betal on Cell Adhesion and Invasion in Human Placenta Trophoblast Cells. Reproduction (2006) 132(2):333-41. doi: $10.1530 /$ rep.1.01112

15. Ingman WV, Robertson SA. The Essential Roles of TGFB1 in Reproduction. Cytokine Growth Factor Rev (2009) 20(3):233-9. doi: 10.1016/j.cytogfr.2009. 05.003

16. Kang X, Zhang X, Liu Z, Xu H, Wang T, He L, et al. Granulocytic MyeloidDerived Suppressor Cells Maintain Feto-Maternal Tolerance by Inducing Foxp3 Expression in CD4+CD25-T Cells by Activation of the TGF-Beta/ Beta-Catenin Pathway. Mol Hum Reprod (2016) 22(7):499-511. doi: $10.1093 /$ molehr/gaw026

17. Shi M, Zhu J, Wang R, Chen X, Mi L, Walz T, et al. Latent TGF-Beta Structure and Activation. Nature (2011) 474(7351):343-9. doi: 10.1038/ nature 10152

18. Lodyga M, Hinz B. TGF-Beta1 - A Truly Transforming Growth Factor in Fibrosis and Immunity. Semin Cell Dev Biol (2020) 101:123-39. doi: 10.1016/ j.semcdb.2019.12.010

19. Travis MA, Sheppard D. TGF-Beta Activation and Function in Immunity. Annu Rev Immunol (2014) 32:51-82. doi: 10.1146/annurev-immunol032713-120257
20. Robertson IB, Rifkin DB. Regulation of the Bioavailability of TGF-Beta and TGF-Beta-Related Proteins. Cold Spring Harb Perspect Biol (2016) 8(6): a021907. doi: 10.1101/cshperspect.a021907

21. Jones K, Ballesteros A, Mentink-Kane M, Warren J, Rattila S, Malech H, et al. PSG9 Stimulates Increase in Foxp3+ Regulatory T-Cells Through the TGF-Beta1 Pathway. PloS One (2016) 11(7):e0158050. doi: 10.1371/ journal.pone.0158050

22. Blois SM, Sulkowski G, Tirado-Gonzalez I, Warren J, Freitag N, Klapp BF, et al. Pregnancy-Specific Glycoprotein 1 (PSG1) Activates TGF-Beta and Prevents Dextran Sodium Sulfate (DSS)-Induced Colitis in Mice. Mucosal Immunol (2014) 7(2):348-58. doi: 10.1038/mi.2013.53

23. Warren J, Im M, Ballesteros A, Ha C, Moore T, Lambert F, et al. Activation of Latent Transforming Growth Factor-Beta1, a Conserved Function for Pregnancy-Specific Beta 1-Glycoproteins. Mol Hum Reprod (2018) 24 (12):602-12. doi: 10.1093/molehr/gay044

24. Morikawa M, Derynck R, Miyazono K. TGF-Beta and the TGF-Beta Family: Context-Dependent Roles in Cell and Tissue Physiology. Cold Spring Harb Perspect Biol (2016) 8(5):a021873. doi: 10.1101/cshperspect.a021873

25. Ciardiello D, Elez E, Tabernero J, Seoane J. Clinical Development of Therapies Targeting Tgfbeta: Current Knowledge and Future Perspectives. Ann Oncol (2020) 31(10):1336-49. doi: 10.1016/j.annonc.2020.07.009

26. Latifi Z, Nejabati HR, Abroon S, Mihanfar A, Farzadi L, Hakimi P, et al. Dual Role of TGF-Beta in Early Pregnancy: Clues From Tumor Progression. Biol Reprod (2019) 100(6):1417-30. doi: 10.1093/biolre/ioz024

27. Hata A, Chen YG. TGF-Beta Signaling From Receptors to Smads. Cold Spring Harb Perspect Biol (2016) 8(9):a022061. doi: 10.1101/cshperspect. a022061

28. Tzavlaki K, Moustakas A. TGF-Beta Signaling. Biomolecules (2020) 10 (3):487. doi: 10.3390/biom10030487

29. Frangogiannis N. Transforming Growth Factor-Beta in Tissue Fibrosis. J Exp Med (2020) 217(3):e20190103. doi: 10.1084/jem.20190103

30. Derynck R, Budi EH. Specificity, Versatility, and Control of TGF-Beta Family Signaling. Sci Signal (2019) 12(570):eaav5183. doi: 10.1126/ scisignal.aav5183

31. Manning BD, Toker A. AKT/PKB Signaling: Navigating the Network. Cell (2017) 169(3):381-405. doi: 10.1016/j.cell.2017.04.001

32. Mayer IA, Arteaga CL. The PI3K/AKT Pathway as a Target for Cancer Treatment. Annu Rev Med (2016) 67:11-28. doi: 10.1146/annurev-med062913-051343

33. Derynck R, Turley SJ, Akhurst RJ. Tgfbeta Biology in Cancer Progression and Immunotherapy. Nat Rev Clin Oncol (2021) 18(1):9-34. doi: 10.1038/ s41571-020-0403-1

34. Schatz F, Guzeloglu-Kayisli O, Arlier S, Kayisli UA, Lockwood CJ. The Role of Decidual Cells in Uterine Hemostasis, Menstruation, Inflammation, Adverse Pregnancy Outcomes and Abnormal Uterine Bleeding. Hum Reprod Update (2016) 22(4):497-515. doi: 10.1093/humupd/dmw004

35. Ferreira LMR, Meissner TB, Tilburgs T, Strominger JL. HLA-G: At the Interface of Maternal-Fetal Tolerance. Trends Immunol (2017) 38(4):27286. doi: 10.1016/j.it.2017.01.009

36. Tafuri A, Alferink J, Moller P, Hammerling GJ, Arnold B. T Cell Awareness of Paternal Alloantigens During Pregnancy. Science (1995) 270(5236):630-3. doi: $10.1126 /$ science.270.5236.630

37. Pollheimer J, Vondra S, Baltayeva J, Beristain AG, Knofler M. Regulation of Placental Extravillous Trophoblasts by the Maternal Uterine Environment. Front Immunol (2018) 9:2597. doi: 10.3389/fimmu.2018.02597

38. Yockey LJ, Iwasaki A. Interferons and Proinflammatory Cytokines in Pregnancy and Fetal Development. Immunity (2018) 49(3):397-412 doi: 10.1016/j.immuni.2018.07.017

39. Nevers T, Kalkunte S, Sharma S. Uterine Regulatory T Cells, IL-10 and Hypertension. Am J Reprod Immunol (2011) 66 Suppl:1 88-92. doi: 10.1111/ j.1600-0897.2011.01040.x

40. Wilczynski JR, Radwan M, Kalinka J. The Characterization and Role of Regulatory T Cells in Immune Reactions. Front Biosci (2008) 13:2266-74. doi: $10.2741 / 2840$

41. Fontenot JD, Rasmussen JP, Williams LM, Dooley JL, Farr AG, Rudensky AY. Regulatory T Cell Lineage Specification by the Forkhead Transcription Factor Foxp3. Immunity (2005) 22(3):329-41. doi: 10.1016/j.immuni. 2005.01 .016 
42. Brunkow ME, Jeffery EW, Hjerrild KA, Paeper B, Clark LB, Yasayko SA, et al. Disruption of a New Forkhead/Winged-Helix Protein, Scurfin, Results in the Fatal Lymphoproliferative Disorder of the Scurfy Mouse. Nat Genet (2001) 27(1):68-73. doi: 10.1038/83784

43. Bennett CL, Christie J, Ramsdell F, Brunkow ME, Ferguson PJ, Whitesell L, et al. The Immune Dysregulation, Polyendocrinopathy, Enteropathy, XLinked Syndrome (IPEX) Is Caused by Mutations of FOXP3. Nat Genet (2001) 27(1):20-1. doi: 10.1038/83713

44. Khattri R, Cox T, Yasayko SA, Ramsdell F. An Essential Role for Scurfin in CD4+CD25+ T Regulatory Cells. Nat Immunol (2003) 4(4):337-42. doi: $10.1038 /$ ni909

45. Aluvihare VR, Kallikourdis M, Betz AG. Regulatory T Cells Mediate Maternal Tolerance to the Fetus. Nat Immunol (2004) 5(3):266-71. doi: 10.1038/ni1037

46. Tilburgs T, Roelen DL, van der Mast BJ, de Groot-Swings GM, Kleijburg C, Scherjon SA, et al. Evidence for a Selective Migration of Fetus-Specific CD4+CD25bright Regulatory $\mathrm{T}$ Cells From the Peripheral Blood to the Decidua in Human Pregnancy. J Immunol (2008) 180(8):5737-45. doi: 10.4049 /jimmunol.180.8.5737

47. Alijotas-Reig J, Llurba E, Gris JM. Potentiating Maternal Immune Tolerance in Pregnancy: A New Challenging Role for Regulatory T Cells. Placenta (2014) 35(4):241-8. doi: 10.1016/j.placenta.2014.02.004

48. Shima T, Sasaki Y, Itoh M, Nakashima A, Ishii N, Sugamura K, et al. Regulatory T Cells Are Necessary for Implantation and Maintenance of Early Pregnancy But Not Late Pregnancy in Allogeneic Mice. J Reprod Immunol (2010) 85(2):121-9. doi: 10.1016/j.jri.2010.02.006

49. Sasaki Y, Sakai M, Miyazaki S, Higuma S, Shiozaki A, Saito S. Decidual and Peripheral Blood CD4+CD25+ Regulatory T Cells in Early Pregnancy Subjects and Spontaneous Abortion Cases. Mol Hum Reprod (2004) 10 (5):347-53. doi: 10.1093/molehr/gah044

50. Gatenby PA, Cameron K, Simes RJ, Adelstein S, Bennett MJ, Jansen RP, et al. Treatment of Recurrent Spontaneous Abortion by Immunization With Paternal Lymphocytes: Results of a Controlled Trial. Am J Reprod Immunol (1993) 29(2):88-94. doi: 10.1111/j.1600-0897.1993.tb00571.x

51. Jin LP, Li DJ, Zhang JP, Wang MY, Zhu XY, Zhu Y, et al. Adoptive Transfer of Paternal Antigen-Hyporesponsive T Cells Induces Maternal Tolerance to the Allogeneic Fetus in Abortion-Prone Matings. J Immunol (2004) 173 (6):3612-9. doi: 10.4049/jimmunol.173.6.3612

52. Wu L, Luo LH, Zhang YX, Li Q, Xu B, Zhou GX, et al. Alteration of Th17 and Treg Cells in Patients With Unexplained Recurrent Spontaneous Abortion Before and After Lymphocyte Immunization Therapy. Reprod Biol Endocrinol (2014) 12:74. doi: 10.1186/1477-7827-12-74

53. Huang N, Chi H, Qiao J. Role of Regulatory T Cells in Regulating FetalMaternal Immune Tolerance in Healthy Pregnancies and Reproductive Diseases. Front Immunol (2020) 11:1023. doi: 10.3389/fimmu.2020.01023

54. Svensson-Arvelund J, Mehta RB, Lindau R, Mirrasekhian E, RodriguezMartinez H, Berg G, et al. The Human Fetal Placenta Promotes Tolerance Against the Semiallogeneic Fetus by Inducing Regulatory $\mathrm{T}$ Cells and Homeostatic M2 Macrophages. J Immunol (2015) 194(4):1534-44. doi: $10.4049 /$ jimmunol.1401536

55. Jones K, Bryant S, Luo J, Kiesler P, Koontz S, Warren J, et al. Recombinant Pregnancy-Specific Glycoprotein 1 has a Protective Role in a Murine Model of Acute Graft-Versus-Host Disease. Biol Blood Marrow Transplant (2019) 25(2):193-203. doi: 10.1016/j.bbmt.2018.09.022

56. Zheng SG, Gray JD, Ohtsuka K, Yamagiwa S, Horwitz DA. Generation Ex Vivo of TGF-Beta-Producing Regulatory T Cells From CD4+CD25Precursors. J Immunol (2002) 169(8):4183-9. doi: 10.4049/jimmunol. 169.8.4183

57. Marie JC, Letterio JJ, Gavin M, Rudensky AY. TGF-Beta1 Maintains Suppressor Function and Foxp3 Expression in CD4+CD25+ Regulatory T Cells. J Exp Med (2005) 201(7):1061-7. doi: 10.1084/jem.20042276

58. Huber S, Schramm C, Lehr HA, Mann A, Schmitt S, Becker C, et al. Cutting Edge: TGF-Beta Signaling Is Required for the in Vivo Expansion and Immunosuppressive Capacity of Regulatory CD4+CD25+ T Cells. J Immunol (2004) 173(11):6526-31. doi: 10.4049/jimmunol.173. 11.6526

59. Chen W, Jin W, Hardegen N, Lei KJ, Li L, Marinos N, et al. Conversion of Peripheral CD4+CD25- Naive T Cells to CD4+CD25+ Regulatory T Cells by
TGF-Beta Induction of Transcription Factor Foxp3. J Exp Med (2003) 198 (12):1875-86. doi: 10.1084/jem.20030152

60. Kedzierska AE, Lorek D, Slawek A, Chelmonska-Soyta A. Tregitopes Regulate the Tolerogenic Immune Response and Decrease the Foetal Death Rate in Abortion-Prone Mouse Matings. Sci Rep (2020) 10 (1):10531. doi: 10.1038/s41598-020-66957-z

61. Wang WJ, Liu FJ, Xin L, Hao CF, Bao HC, Qu QL, et al. Adoptive Transfer of Pregnancy-Induced CD4+CD25+ Regulatory T Cells Reverses the Increase in Abortion Rate Caused by Interleukin 17 in the CBA/Jxbalb/C Mouse Model. Hum Reprod (2014) 29(5):946-52. doi: 10.1093/humrep/deu014

62. Hanna J, Wald O, Goldman-Wohl D, Prus D, Markel G, Gazit R, et al. CXCL12 Expression by Invasive Trophoblasts Induces the Specific Migration of CD16- Human Natural Killer Cells. Blood (2003) 102 (5):1569-77. doi: 10.1182/blood-2003-02-0517

63. Keskin DB, Allan DS, Rybalov B, Andzelm MM, Stern JN, Kopcow HD, et al. Tgfbeta Promotes Conversion of CD16+ Peripheral Blood NK Cells Into CD16- NK Cells With Similarities to Decidual NK Cells. Proc Natl Acad Sci USA (2007) 104(9):3378-83. doi: 10.1073/pnas.0611098104

64. Sanjabi S, Oh SA, Li MO. Regulation of the Immune Response by TGF-Beta: From Conception to Autoimmunity and Infection. Cold Spring Harb Perspect Biol (2017) 9(6):a022236. doi: 10.1101/cshperspect.a022236

65. Moffett-King A. Natural Killer Cells and Pregnancy. Nat Rev Immunol (2002) 2(9):656-63. doi: 10.1038/nri886

66. Lash GE, Schiessl B, Kirkley M, Innes BA, Cooper A, Searle RF, et al. Expression of Angiogenic Growth Factors by Uterine Natural Killer Cells During Early Pregnancy. J Leukoc Biol (2006) 80(3):572-80. doi: 10.1189/ jlb.0406250

67. Clark DA, Vince G, Flanders KC, Hirte H, Starkey P. CD56+ Lymphoid Cells in Human First Trimester Pregnancy Decidua as a Source of Novel Transforming Growth Factor-Beta 2-Related Immunosuppressive Factors. Hum Reprod (1994) 9(12):2270-7. doi: 10.1093/oxfordjournals.humrep. a138436

68. Jokhi PP, King A, Sharkey AM, Smith SK, Loke YW. Screening for Cytokine Messenger Ribonucleic Acids in Purified Human Decidual Lymphocyte Populations by the Reverse-Transcriptase Polymerase Chain Reaction. J Immunol (1994) 153(10):4427-35.

69. Spaggiari GM, Capobianco A, Abdelrazik H, Becchetti F, Mingari MC, Moretta L. Mesenchymal Stem Cells Inhibit Natural Killer-Cell Proliferation, Cytotoxicity, and Cytokine Production: Role of Indoleamine 2,3Dioxygenase and Prostaglandin E2. Blood (2008) 111(3):1327-33. doi: 10.1182/blood-2007-02-074997

70. Shokri MR, Bozorgmehr M, Ghanavatinejad A, Falak R, Aleahmad M, Kazemnejad S, et al. Human Menstrual Blood-Derived Stromal/Stem Cells Modulate Functional Features of Natural Killer Cells. Sci Rep (2019) 9 (1):10007. doi: 10.1038/s41598-019-46316-3

71. Jena MK, Nayak N, Chen K, Nayak NR. Role of Macrophages in Pregnancy and Related Complications. Arch Immunol Ther Exp (Warsz) (2019) 67 (5):295-309. doi: 10.1007/s00005-019-00552-7

72. Shapouri-Moghaddam A, Mohammadian S, Vazini H, Taghadosi M, Esmaeili SA, Mardani F, et al. Macrophage Plasticity, Polarization, and Function in Health and Disease. J Cell Physiol (2018) 233(9):6425-40. doi: $10.1002 /$ jcp. 26429

73. Zhang YH, He M, Wang Y, Liao AH. Modulators of the Balance Between M1 and M2 Macrophages During Pregnancy. Front Immunol (2017) 8:120. doi: 10.3389/fimmu.2017.00120

74. Trundley A, Moffett A. Human Uterine Leukocytes and Pregnancy. Tissue Antigens (2004) 63(1):1-12. doi: 10.1111/j.1399-0039.2004.00170.x

75. Svensson-Arvelund J, Ernerudh J. The Role of Macrophages in Promoting and Maintaining Homeostasis at the Fetal-Maternal Interface. Am J Reprod Immunol (2015) 74(2):100-9. doi: 10.1111/aji.12357

76. Nagamatsu T, Schust DJ. The Contribution of Macrophages to Normal and Pathological Pregnancies. Am J Reprod Immunol (2010) 63(6):460-71. doi: 10.1111/j.1600-0897.2010.00813.x

77. Ning F, Liu H, Lash GE. The Role of Decidual Macrophages During Normal and Pathological Pregnancy. Am J Reprod Immunol (2016) 75(3):298-309. doi: $10.1111 /$ aji.12477

78. Ding J, Yang C, Cheng Y, Wang J, Zhang S, Yan S, et al. TrophoblastDerived IL-6 Serves as an Important Factor for Normal Pregnancy by 
Activating Stat3-Mediated M2 Macrophages Polarization. Int Immunopharmacol (2021) 90:106788. doi: 10.1016/j.intimp.2020.106788

79. Kim SY, Romero R, Tarca AL, Bhatti G, Kim CJ, Lee J, et al. Methylome of Fetal and Maternal Monocytes and Macrophages at the Feto-Maternal Interface. Am J Reprod Immunol (2012) 68(1):8-27. doi: 10.1111/j.16000897.2012.01108.x

80. Pavlov OV, Selutin AV, Pavlova OM, Selkov SA. Two Patterns of Cytokine Production by Placental Macrophages. Placenta (2020) 91:1-10. doi: 10.1016/j.placenta.2020.01.005

81. Chekol Abebe E, Asmamaw Dejenie T, Mengie Ayele T, Dagnew Baye N, Agegnehu Teshome A, Tilahun Muche Z. The Role of Regulatory B Cells in Health and Diseases: A Systemic Review. J Inflammation Res (2021) 14:7584. doi: $10.2147 /$ JIR.S286426

82. Rosser EC, Mauri C. Regulatory B Cells: Origin, Phenotype, and Function. Immunity (2015) 42(4):607-12. doi: 10.1016/j.immuni.2015.04.005

83. Moore TC, Gonzaga LM, Mather JM, Messer RJ. Hasenkrug KJ. B Cell Requirement for Robust Regulatory T Cell Responses to Friend Retrovirus Infection. mBio (2017) 8(4):e01122-17. doi: 10.1128/mBio.01122-17

84. Jensen F, Muzzio D, Soldati R, Fest S, Zenclussen AC. Regulatory B10 Cells Restore Pregnancy Tolerance in a Mouse Model. Biol Reprod (2013) 89 (4):90. doi: 10.1095/biolreprod.113.110791

85. Muzzio DO, Soldati R, Ehrhardt J, Utpatel K, Evert M, Zenclussen AC, et al. B Cell Development Undergoes Profound Modifications and Adaptations During Pregnancy in Mice. Biol Reprod (2014) 91(5):115. doi: 10.1095/ biolreprod.114.122366

86. Nouel A, Pochard P, Simon Q, Segalen I, Le Meur Y, Pers JO, et al. B-Cells Induce Regulatory T Cells Through TGF-Beta/IDO Production in a CTLA-4 Dependent Manner. J Autoimmun (2015) 59:53-60. doi: 10.1016/ j.jaut.2015.02.004

87. Slawek A, Lorek D, Kedzierska AE, Chelmonska-Soyta A. Regulatory B Cells With IL-35 and IL-10 Expression in a Normal and Abortion-Prone Murine Pregnancy Model. Am J Reprod Immunol (2020) 83(3):e13217. doi: 10.1111/ aji.13217

88. Boss AL, Chamley LW, James JL. Placental Formation in Early Pregnancy: How Is the Centre of the Placenta Made? Hum Reprod Update (2018) 24 (6):750-60. doi: 10.1093/humupd/dmy030

89. Xu YY, Wang SC, Li DJ, Du MR. Co-Signaling Molecules in Maternal-Fetal Immunity. Trends Mol Med (2017) 23(1):46-58. doi: 10.1016/j.molmed. 2016.11.001

90. Fu YY, Ren CE, Qiao PY, Meng YH. Uterine Natural Killer Cells and Recurrent Spontaneous Abortion. Am J Reprod Immunol (2021) 86(2): e13433. doi: 10.1111/aji.13433

91. Bai K, Li X, Zhong J, Ng EHY, Yeung WSB, Lee CL, et al. Placenta-Derived Exosomes as a Modulator in Maternal Immune Tolerance During Pregnancy. Front Immunol (2021) 12:671093. doi: 10.3389/fimmu.2021.671093

92. Chen X, Guo DY, Yin TL, Yang J. Non-Coding Rnas Regulate Placental Trophoblast Function and Participate in Recurrent Abortion. Front Pharmacol (2021) 12:646521. doi: 10.3389/fphar.2021.646521

93. Freis A, Schlegel J, Daniel V, Jauckus J, Strowitzki T, Germeyer A. Cytokines in Relation to Hcg Are Significantly Altered in Asymptomatic Women With Miscarriage - A Pilot Study. Reprod Biol Endocrinol (2018) 16(1):93. doi: 10.1186/s12958-018-0411-5

94. Saifi B, Rezaee SA, Tajik N, Ahmadpour ME, Ashrafi M, Vakili R, et al. Th17 Cells and Related Cytokines in Unexplained Recurrent Spontaneous Miscarriage at the Implantation Window. Reprod BioMed Online (2014) 29(4):481-9. doi: 10.1016/j.rbmo.2014.06.008

95. Wang WJ, Liu FJ, Qu HM, Hao CF, Qu QL, Xiong W, et al. Regulation of the Expression of Th17 Cells and Regulatory T Cells by IL-27 in Patients With Unexplained Early Recurrent Miscarriage. J Reprod Immunol (2013) 99(12):39-45. doi: 10.1016/j.jri.2013.04.002

96. Qian J, Zhang N, Lin J, Wang C, Pan X, Chen L, et al. Distinct Pattern of Th17/Treg Cells in Pregnant Women With a History of Unexplained Recurrent Spontaneous Abortion. Biosci Trends (2018) 12(2):157-67. doi: 10.5582/bst.2018.01012

97. Gallino L, Calo G, Hauk V, Fraccaroli L, Grasso E, Vermeulen M, et al. VIP Treatment Prevents Embryo Resorption by Modulating Efferocytosis and Activation Profile of Maternal Macrophages in the Cbaxdba Resorption Prone Model. Sci Rep (2016) 6:18633. doi: 10.1038/srep18633
98. Ma Y, Yang Q, Fan M, Zhang L, Gu Y, Jia W, et al. Placental Endovascular Extravillous Trophoblasts (Enevts) Educate Maternal T-Cell Differentiation Along the Maternal-Placental Circulation. Cell Prolif (2020) 53(5):e12802. doi: $10.1111 /$ cpr.12802

99. Yang M, Luo J, Li Y, Xu L. Systems Pharmacology-Based Research on the Mechanism of Tusizi-Sangjisheng Herb Pair in the Treatment of Threatened Abortion. BioMed Res Int (2020) 2020:4748264. doi: 10.1155/ 2020/4748264

100. Fernandez L, Castro I, Arroyo R, Alba C, Beltran D, Rodriguez JM. Application of Ligilactobacillus Salivarius CECT5713 to Achieve Term Pregnancies in Women With Repetitive Abortion or Infertility of Unknown Origin by Microbiological and Immunological Modulation of the Vaginal Ecosystem. Nutrients (2021) 13(1):162. doi: 10.3390/nu13010162

101. Shenoy V, Kanasaki K, Kalluri R. Pre-Eclampsia: Connecting Angiogenic and Metabolic Pathways. Trends Endocrinol Metab (2010) 21(9):529-36. doi: 10.1016/j.tem.2010.05.002

102. Phipps EA, Thadhani R, Benzing T, Karumanchi SA. Pre-Eclampsia: Pathogenesis, Novel Diagnostics and Therapies. Nat Rev Nephrol (2019) 15(5):275-89. doi: 10.1038/s41581-019-0119-6

103. Vinayagam V, Bobby Z, Habeebullah S, Chaturvedula L, Bharadwaj SK. Maternal and Cord Blood Plasma Seng and TGF-Betal in Patients With Hypertensive Disorders of Pregnancy: A Pilot Study in a South Indian Population. J Clin Diagn Res (2017) 11(3):QC32-4. doi: 10.7860/JCDR/2017/ 22790.9600

104. Chen J, Tan W, Wang D, Zhao L, Gao H, Zhang N, et al. Association of Foxp3 and TGF-Betal Polymorphisms With Pre-Eclampsia Risk in Chinese Women. Genet Test Mol Biomarkers (2019) 23(3):180-87. doi: 10.1089/ gtmb.2018.0279

105. Yu L, Kuang LY, He F, Du LL, Li QL, Sun W, et al. The Role and Molecular Mechanism of Long Nocoding RNA-MEG3 in the Pathogenesis of Preeclampsia. Reprod Sci (2018) 25(12):1619-28. doi: 10.1177/ 1933719117749753

106. Molvarec A, Szarka A, Walentin S, Beko G, Karadi I, Prohaszka Z, et al. Serum Leptin Levels in Relation to Circulating Cytokines, Chemokines, Adhesion Molecules and Angiogenic Factors in Normal Pregnancy and Preeclampsia. Reprod Biol Endocrinol (2011) 9:124. doi: 10.1186/1477-78279-124

107. Huppertz B. Placental Origins of Preeclampsia: Challenging the Current Hypothesis. Hypertension (2008) 51(4):970-5. doi: 10.1161/ HYPERTENSIONAHA.107.107607

108. Yi Y, Cheng JC, Klausen C, Leung PCK. TGF-Betal Inhibits Human Trophoblast Cell Invasion by Upregulating Cyclooxygenase-2. Placenta (2018) 68:44-51. doi: 10.1016/j.placenta.2018.06.313

109. Cheng JC, Chang HM, Leung PCK. TGF-Betal Inhibits Human Trophoblast Cell Invasion by Upregulating Connective Tissue Growth Factor Expression. Endocrinology (2017) 158(10):3620-28. doi: 10.1210/en.2017-00536

110. Xu XH, Jia Y, Zhou X, Xie D, Huang X, Jia L, et al. Downregulation of Lysyl Oxidase and Lysyl Oxidase-Like Protein 2 Suppressed the Migration and Invasion of Trophoblasts by Activating the TGF-Beta/Collagen Pathway in Preeclampsia. Exp Mol Med (2019) 51(2):1-12. doi: 10.1038/s12276-0190211-9

111. Liu E, Liu Z, Zhou Y, Chen M, Wang L, Li J. Microrna1423p Inhibits Trophoblast Cell Migration and Invasion by Disrupting the Tgfbeta1/Smad3 Signaling Pathway. Mol Med Rep (2019) 19(5):3775-82. doi: 10.3892/ mmr.2019.9997

112. Venkatesha S, Toporsian M, Lam C, Hanai J, Mammoto T, Kim YM, et al. Soluble Endoglin Contributes to the Pathogenesis of Preeclampsia. Nat Med (2006) 12(6):642-9. doi: 10.1038/nm1429

113. Zhou C, Yan Q, Zou QY, Zhong XQ, Tyler CT, Magness RR, et al. Sexual Dimorphisms of Preeclampsia-Dysregulated Transcriptomic Profiles and Cell Function in Fetal Endothelial Cells. Hypertension (2019) 74(1):15463. doi: 10.1161/HYPERTENSIONAHA.118.12569

114. Zhang J, Dunk CE, Shynlova O, Caniggia I, Lye SJ. Tgfb1 Suppresses the Activation of Distinct Dnk Subpopulations in Preeclampsia. EBioMedicine (2019) 39:531-39. doi: 10.1016/j.ebiom.2018.12.015

115. Blankley RT, Fisher C, Westwood M, North R, Baker PN, Walker MJ, et al. A Label-Free Selected Reaction Monitoring Workflow Identifies a Subset of Pregnancy Specific Glycoproteins as Potential Predictive Markers of Early- 
Onset Pre-Eclampsia. Mol Cell Proteomics (2013) 12(11):3148-59. doi: $10.1074 /$ mcp.M112.026872

Conflict of Interest: The authors declare that the research was conducted in the absence of any commercial or financial relationships that could be construed as a potential conflict of interest.

Publisher's Note: All claims expressed in this article are solely those of the authors and do not necessarily represent those of their affiliated organizations, or those of the publisher, the editors and the reviewers. Any product that may be evaluated in this article, or claim that may be made by its manufacturer, is not guaranteed or endorsed by the publisher.

Copyright (c) 2021 Yang, Dai, Yuan, Zheng, Liu, Deng, Tan, Chen, Zhang, Zhao and Cheng. This is an open-access article distributed under the terms of the Creative Commons Attribution License (CC BY). The use, distribution or reproduction in other forums is permitted, provided the original author(s) and the copyright owner(s) are credited and that the original publication in this journal is cited, in accordance with accepted academic practice. No use, distribution or reproduction is permitted which does not comply with these terms. 